\title{
LPS Enhances the Chemosensitivity of Oxaliplatin in HT29 Cells via GSDMD-Mediated Pyroptosis
}

This article was published in the following Dove Press journal:

Cancer Management and Research

Li-Sha Wu'
Yabin Liu'
Xiao-wei Wang'
Bin Xu'
Yan-Ling Lin'
Yu Song
Yi Dong '
Jin-Lai Liu ID
Xiang-Jie Wang'
Shuang Liu'
Peng Kong
Mei Han ${ }^{2}$
Bing-Hui Li'
'Department of Surgery, Fourth Hospital
of Hebei Medical University, Shijiazhuang
0500II, People's Republic of China;
'Department of Biochemistry and
Molecular Biology, College of Basic
Medicine, Key Laboratory of Medical
Biotechnology of Hebei Province, Hebei
Medical University, Shijiazhuang 0500I7,
People's Republic of China

Correspondence: Bing-Hui Li

Department of Surgery, The Fourth Hospital of Hebei Medical University, 12 Jiankang Road, Shijiazhuang, Hebei 050000, People's Republic of China

Tel +86 3II 86265639

Fax +86-03 I I-86265557

Email Ibh58hebei@I63.com

Mei Han

Department of Biochemistry and Molecular Biology, College of Basic Medicine, Key Laboratory of Medical Biotechnology of Hebei Province, Hebei Medical University, No. 36I, Zhongshan East Road, Shijiazhuang 0500 I7, People's Republic of China

Tel +863 II 86265639

Fax +86-03। I-86265557

Email hanmei@hebmu.edu.cn
Introduction: Pyroptosis induced by lipopolysaccharide (LPS) is a dissolved form of cell death. The molecular marker gasdermin D, specifically GSDMD-N, is critically required for the induction of pyroptosis. Recently, there have been studies showing that LPS is closely related to tumor biology.

Methods: Specimens from 40 patients with colorectal cancer (CRC) were collected. Eight- to twelve-week-old C57BL6 male mice $(n=30)$ were raised. Immunohistochemistry and Western blot were performed to test the expression of GSDMD. Moreover, cytotoxicity assay, IL-18 and IL-1 $\beta$ ELISA, Annexin V and PI stain, and wound healing assay were also made. Gene Expression Profiling Interactive Analysis (GEPIA) was used to verify the expression of GSDMD and overall survival of CRC patients with a high/low expression of GSDMD.

Results: In the research, we showed that the poor prognosis in CRC patients was significantly related to the GSDMD expression and significantly down-regulated in human colorectal cancer (CRC) tissues. Treatment with LPS, but not TNF- $\alpha$, induced pyroptosis via promoting the expression of GSDMD and GSDMD-N membrane translocation and enhanced chemosensitivity in response to L-OHP in HT29 cells. Furthermore, the enforced expression of GSDMD in HT29 cells reduced cell survival and induced cell death.

Discussion: These results of studies suggest that the low expression of GSDMD correlates with a poor CRC prognosis, and that pyroptosis induced by LPS may improve the anti-cancer effect of L-OHP, inhibiting the tumorigenesis of CRC by activating GSDMD. Our findings lay the foundation for further development of GSDMD serving as an important prognostic biomarker and a valid CRC therapeutic target.

Keywords: colorectal cancer, lipopolysaccharide, chemotherapy, pyroptosis, HT29 cells

\section{Introduction}

Colorectal cancer (CRC) is one of the most commonly diagnosed cancers and causes of death from cancer across the world. ${ }^{1}$ In addition, the morbidity of CRC all over the world has increased rapidly over the past decade. ${ }^{2}$ We have made many efforts in order to improve treatment of patients with CRC. However, the resistance to traditional drugs and postoperative recurrence still make most patients die from this disease. ${ }^{3}$ L-OHP, a third-generation platinum compound, which has been developed as an alternative pharmacological compound to cisplatin, displays an anti-tumor effect in CRC. ${ }^{4,5}$ But since intrinsic or acquired resistance to L-OHP has affected its chemotherapeutic sensitivity, reversing the L-OHP resistance of the CRC is a practical method for enhancing chemosensitivity. ${ }^{6,7}$

The outer membrane of gram-negative bacteria is made up of Lipopolysaccharide (LPS). ${ }^{8}$ The potential use of bacteria or endotoxins of the 
effects of anti-tumor has been widely researched for decades. ${ }^{9}$ Although now LPS is not used to treat cancer due to its toxicities, the underlying theory was right has been revealed by the accumulating evidence ${ }^{10,11}$ One experiment has verified that the cancer cell survival can be inhibited by LPS. ${ }^{12}$ Functional studies show that LPS reduces cancer survival, invasion, and proliferation via various mechanisms, suggesting that LPS is an effective cancer progression management strategy. ${ }^{13}$

Although the enjoyment in LPS which serves as a cancer therapeutic drugs has diminished, whether LPS attacks cancer cells with the direct function remains controversial. The lethality of LPS-induced is largely dependent on the activated caspase- 1 encoded by Casp $1 .{ }^{14-16}$ GSDMD is cleaved into pore-forming peptides by activating caspase- 1 that subsequently leads to pyroptosis, a dissolved form of cell death releasing inflammatory cytokines like IL-1 $\beta$ and IL-18. ${ }^{17-19}$ Previous research has revealed that GSDMD expression acted differently with upper gastrointestinal cancer and suppressed gastric cancer development. ${ }^{20}$ However, the potential roles of pyroptosis induced by LPS in CRC are still unclear. Therefore, this study aims at exploring how LPS enhances the chemosensitivity of oxaliplatin in CRC via GSDMDmediated pyroptosis.

\section{Patients and Methods}

\section{Patients}

Obtained human tissue samples include cancer tissues and their paired adjacent normal mucosa from CRC patients who had recovered surgery between November 2016 and October 2017, at the Hebei Medical University Fourth Hospital, Shijiazhuang, China. Specimens from 40 patients were collected. The specimens, after being cut off during surgery, were quickly stored in liquid nitrogen at $-80^{\circ} \mathrm{C}$. At the same time, paraffin-embedded tissues from 244 colon cancer patients (treated from November 2012 to October 2014) were screened based on the original pathologic diagnosis. The study was approved by the Ethics and the Academic Committees of Hebei Medical University (Shijiazhuang, China). The informed written consent was obtained from all the patients, and was also approved by the Ethics and the Academic Committees of Hebei Medical University.

\section{Experimental Animals}

Eight- to twelve-week-old C57BL6 male mice $(n=30)$ were raised at the Animal Resource Core Facility of
Hebei Medical University where have specific clean conditions. The mice were fed with standard laboratory chow, and kept on 12-hr light/dark cycles. All protocols were approved by the Institutional Animal Care and Use Committee of Hebei Medical University. And all the procedure complied with Chinese Guidelines of ethical review for the welfare of the laboratory animal. The mice were randomly assigned to four different experimental groups. The schematic experimental design is represented in Figure 1A. The mice were executed and dissected at day 70, and their colonies, from the ileocecal junction to the anal verge, were removed. Six mice selected randomly from the group of colitis-associated colon cancer and divided into two groups. One group was intraperitoneal injected L-OHP (10 mg/kg body weight). Another group injected L-OHP (10 mg/kg) and LPS $(1 \mathrm{mg} / \mathrm{kg})$. Cut open the colons along the main axis, then washed these colons with phosphatebuffered saline. One part was stored for biochemical assays and another one was used for histology assays. Histomorphology and grading of regression in CRC treated with chemotherapy. ${ }^{21}$

\section{Cell Culture}

Human colon cancer cell lines of HT29 were bought from Shanghai Institute of Life Sciences, China. All the cells were cultured as monolayer cultures in a McCoy's 5A (SH30200.01, HyClone) medium, supplemented with $10 \%$ fetal bovine serum, double antibiotics in a condition of $5 \% \mathrm{CO}_{2}$, all in a cell holder at $37^{\circ} \mathrm{C}$.

\section{Immunohistochemistry}

Blocked sections with $0.3 \% \mathrm{H}_{2} \mathrm{O}_{2}$, followed by preincubation with $5 \%$ normal serum and incubation with primary anti-GSDMD $(2.5 \mu \mathrm{g} / \mathrm{mL}$, DF-12,275, Affinity, USA), overnight at $4{ }^{\circ} \mathrm{C}$. The sections were incubated with the biotinylated secondary antibody, and then the sections were incubated with streptavidin-horseradish peroxidase and diaminobenzidine, and stained with hematoxylin. The staining intensities of GSDMD were determined by measurement of MOD, using Image-Pro Plus System.

\section{Western Blot Analysis}

Total protein extracts were prepared by a RIPA Buffer plus protease inhibitors (Roche). Membrane protein extracts were prepared by using a ProteoPrep ${ }^{\circledR}$ 


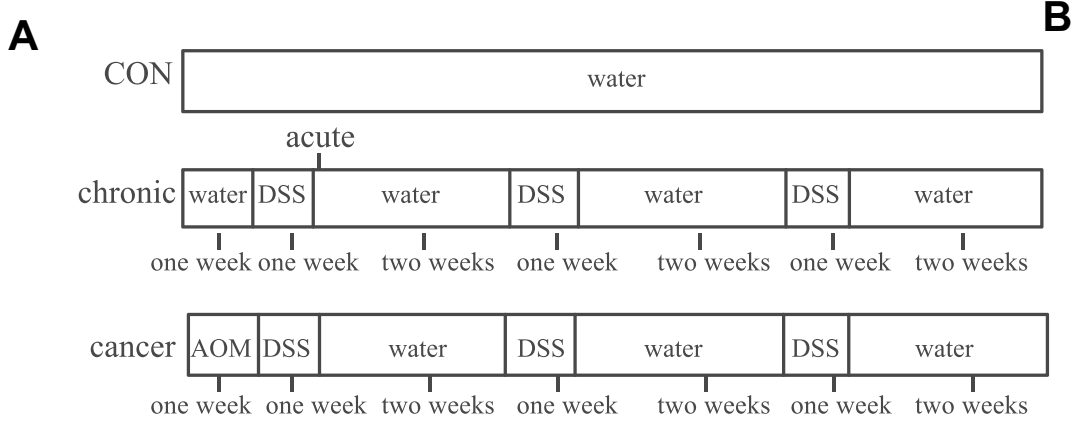

C

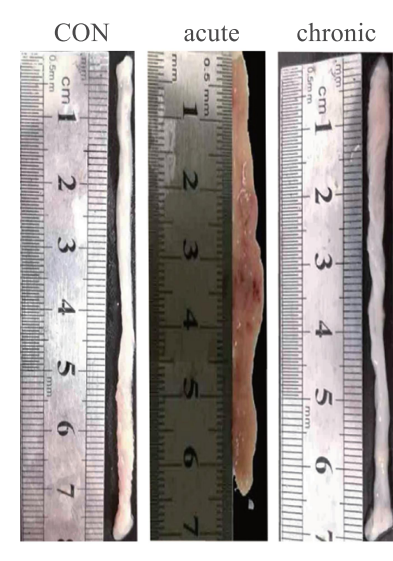

E

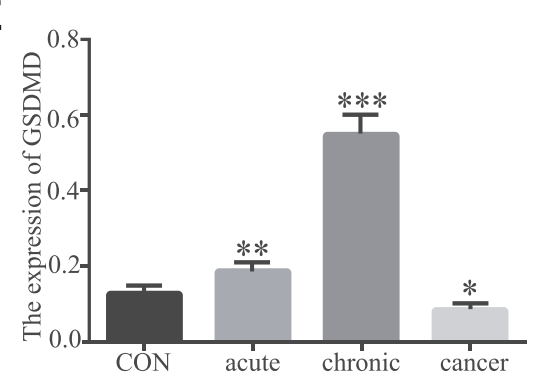

D
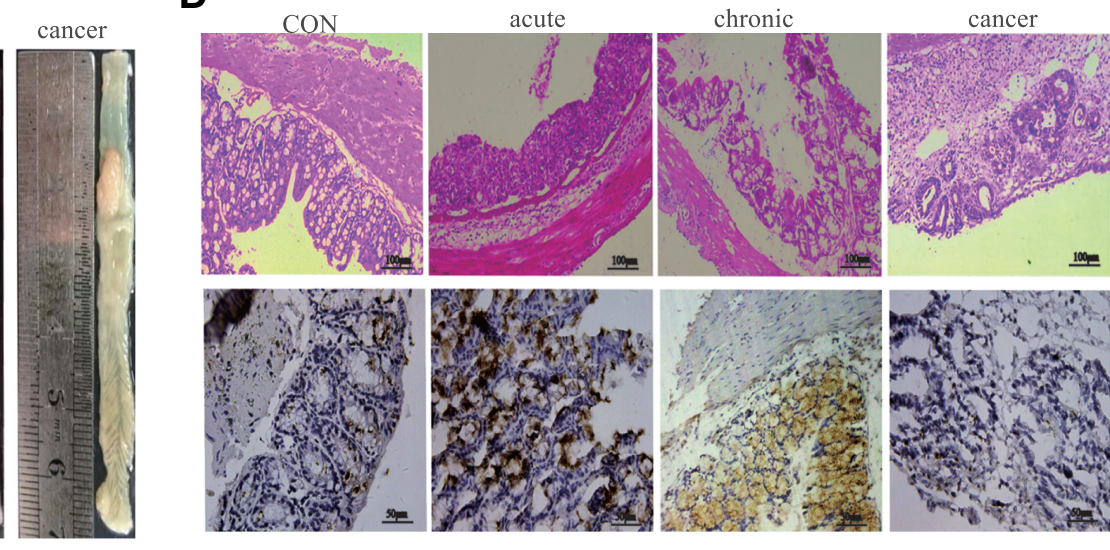

$\mathrm{F}$
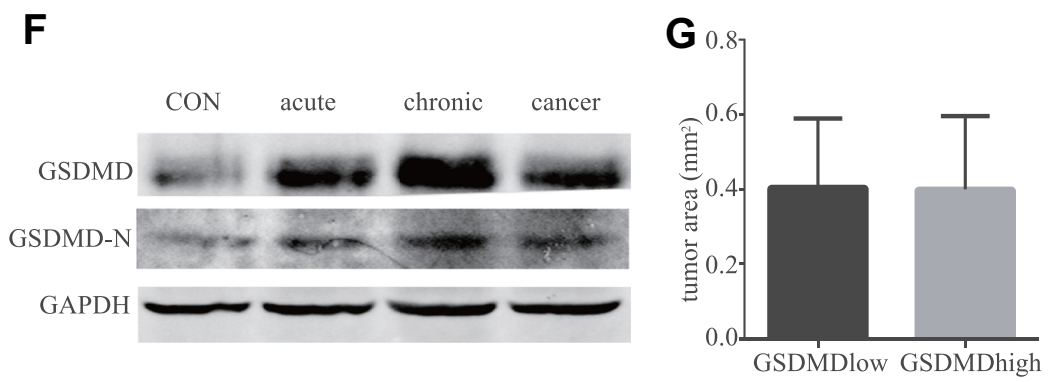

Figure I LPS improves anti-cancer effect of oxaliplatin in mice in vivo experiment. (A) Experimental protocol for acute colitis, chronic colitis and colitis-associated colon carcinogenesis model (AOM $10 \mathrm{mg} / \mathrm{kg} 2.5 \%$ DSS). (B) Relative body weight curves of WT mice with chronic colitis, colitis-associated colon carcinogenesis and control group $(n=6)$. (C) On day 14 and 70, removing the colons and analyzing tumor lesions microscopically. Representative gross pathology of the descending colon and rectum at the end of the AOM/DSS protocol on day 70. (D-F) Histopathology of colonials in different phases of model establishment. Western blot analyses and IHC of GSDMD and GSDMD-N in each group $(n=6)$. (G) The effects of GSDMD deletion on the tumor volumes. $* P<0.05$, $* * P<0.01$, $* * * P<0.001$ compared with control group.

Membrane Extraction Kit (p0033, Beyotime, China) Separated the lysates containing equal amounts of protein by SDS-PAGE and electroblotted onto polyvinylidene difluoride membranes by a semi-dry transfer system (Bio-Rad). Blots were blocked with 5\% normal goat serum in TBST for $2 \mathrm{~h}$ at $25^{\circ} \mathrm{C}$, then probed with rabbit anti-GSDMD (1.5 $\mu \mathrm{g} / \mathrm{mL}, \mathrm{DF}-12,275$, Affinity, USA), rabbit anti-caspase-1/d (1.5 $\mu \mathrm{g} / \mathrm{mL}$, ab16329, Abcam), and rabbit anti-GAPDH (1:800, sc-32,233, Santa Cruz) at $4{ }^{\circ} \mathrm{C}$ overnight. Then, the blots were visualized on an Odyssey Infrared Imaging System (LiCor Biosciences).

\section{Cytotoxicity Assay, IL-I8, and IL- I $\beta$ ELISA} Measured the cell death with LDH assay using a CytoTox 96 Non-Radioactive Cytotoxicity Assay kit (Promega). The CellTiterGlo Luminescent Cell Viability Assay (Promega) was used to determine the cell viability. To measure IL-18 and IL- $1 \beta$ release, the primary HT29 cells were primed with LPS $(2.5,5,10 \mu \mathrm{g} / \mathrm{mL})$ or TNF- $\alpha(10 \mathrm{ng} / \mathrm{mL}$ and $20 \mathrm{ng} / \mathrm{mL})$ at different points in time $(3,6,12$, and $24 \mathrm{~h})$ and the released mature IL-18 and IL- $1 \beta$ levels were determined by using the IL-18 and IL-1 $\beta$ ELISA kit (Neobioscience Technology Company). 


\section{MTT}

HT29 cells were seeded into a 96-well plate and cultured for $24 \mathrm{~h}$. The primary HT29 cells were primed with L-OHP $(20,40,60,80 \mu \mathrm{g} / \mathrm{mL})$, siGSDMD $(20 \mu \mathrm{L})$ or LPS $(10 \mu \mathrm{g} / \mathrm{mL})$ at different points in time $(3,6,12$, and 24h). $15 \mu \mathrm{L}(5 \mathrm{mg} / \mathrm{mL})$ MTT was added to each well for $4 \mathrm{~h}$, after which the supernatants were removed carefully. Next, the MTT formazan was dissolved in $150 \mu \mathrm{L}$ DMSO and OD values were measured using a microplate reader at $492 \mathrm{~nm}$. All assays were repeated three times.

\section{Annexin $\mathrm{V}$ and PI Staining}

The primary HT29 cells were primed with LPS $(10 \mu \mathrm{g} /$ $\mathrm{mL})$, L-OHP $(20 \mu \mathrm{g} / \mathrm{mL})$ or siRNA $(20 \mu \mathrm{g} / \mathrm{mL})$. After $24 \mathrm{~h}$ of treatment, the HT29 cells were performed using the Annexin V-FITC/PI Apoptosis Kit (BD
Biosciences, USA) according to the manufacturer's protocol. In brief, cells were resuspended in binding buffer. Cells were then incubated with $5 \mu \mathrm{L}$ Annexin V-FITC reagent and $5 \mu \mathrm{L}$ PI in the dark for $15 \mathrm{~min}$. The samples were analyzed by flow cytometry with BD FACSCalibur.

\section{PI Staining}

The HT29 cells were pretreated with LPS $(10 \mu \mathrm{g} / \mathrm{mL})$ for different points in time (3, 6, 12, and 24h). LPS-primed HT29 cells were pretreated with PI $(5 \mu \mathrm{L})$ for $1 \mathrm{~h}$.

\section{Wound Healing Assay}

The cells were grown in 6 well plates. Serum starvation for $24 \mathrm{~h}$ before use. An approximately $4-5 \mathrm{~mm}$ wound was scratched and washed three times with PBS $2 \mathrm{~mL}$ of McCoy's 5A and with $2 \%$ FBS at LPS $(10 \mu \mathrm{g} / \mathrm{mL})$, then
A

B

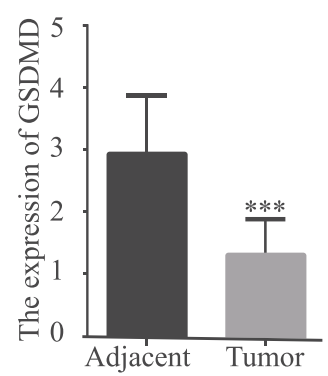

C GSDMD high expression GSDMD low expression

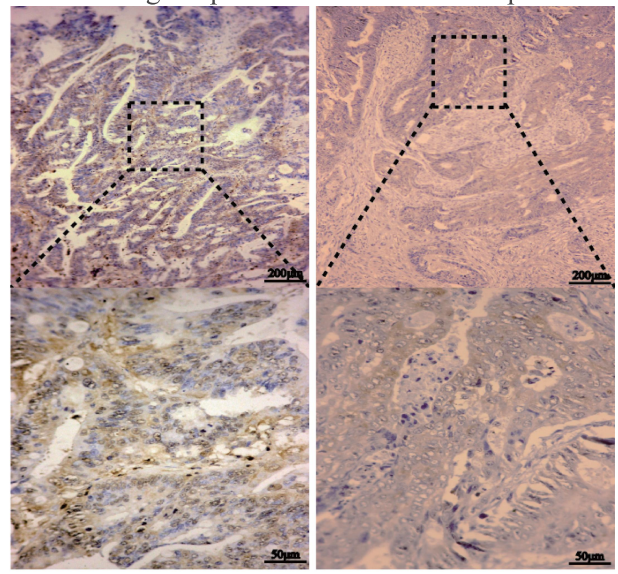

$\mathbf{F}$

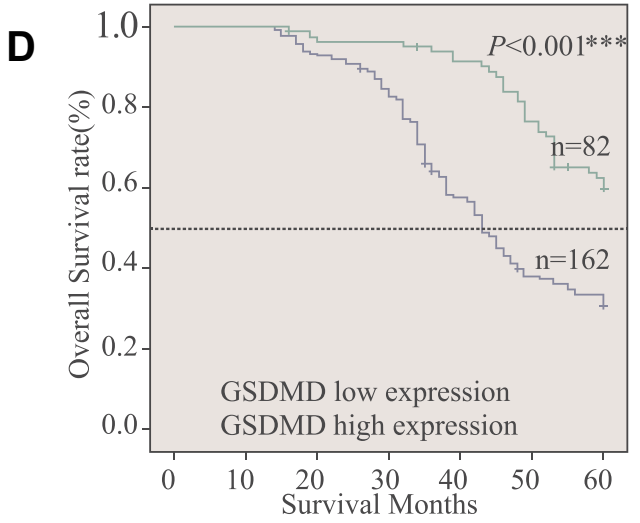

E

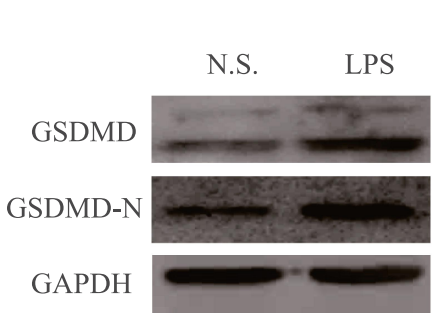

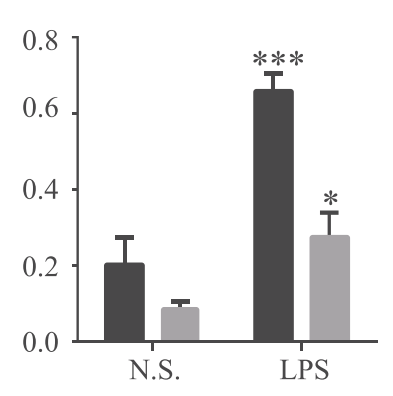

GSDMD GSDMD-N

Figure 2 The GSDMD expression is reduced in human colorectal cancer tissues and is significantly related to the overall survival of CRC patients. (A and B) The protein levels of GSDMD in CRC patients and the tissue samples of the corresponding non-malignant adjacent were measured by Western blot analysis ( $\mathrm{n}=40$ ). (C) Immunohistochemical analysis of GSDMD expression in human colorectal cancer tissues ( $n=244$ ). (D) The Kaplan-Meier method was performed to compare the overall survival (OS) in 244 patients with CRC with the low and high GSDMD protein expression level groups. (E and F) Using Western blot analysis to assess the GSDMD and GSDMD-N expression in colorectal cancer tissue culture with LPS $(10 \mu \mathrm{g} / \mathrm{mL})$ or normal saline for $24 \mathrm{~h}(\mathrm{n}=6)$. Data are shown as the mean \pm SD. $* \mathrm{P}<0.05$, $* * * \mathrm{P}<0.00 \mathrm{I}$ compared with the control group. 
L-OHP $(20 \mu \mathrm{mol} / \mathrm{L})$ and siGSDMD $(20 \mu \mathrm{g} / \mathrm{mL})$ were added. After $24 \mathrm{~h}$ of culture, the migration of cells in each group was observed.

\section{Verification of Expression of GSDMD Using Gene Expression Profiling Interactive Analysis (GEPIA)}

The expression level of GSDMD in the normal and CRC samples was ascertained using GEPIA (http://gepia.can

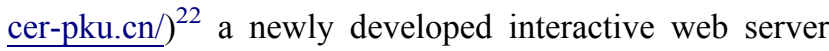
for analyzing the gene expression data of large consortium projects such as The Cancer Genome Atlas and the Genotype Tissue Expression project.

\section{Overall Survival Analysis of the CRC Patients with High/Low Expression of GSDMD}

The Kaplan-Meier Plotter (http://kmplot.com/analysis/ index.php? $\mathrm{p}=$ background $)^{23,24}$ an online analysis tool, was performed to evaluate the overall survival analysis of the CRC patients with high/low expressions of GSDMD. The primary purpose of the tool is a meta-analysis-based discovery and validation of survival biomarkers. The group of patients was obtained from the public database "KaplanMeier Plotter" which includes gene chip and RNA-seq datasources for the databases include GEO, EGA, and TCGA. The comparison of overall survival was made between

Table I Association Between GSDMD Expression and Clinic Pathological Factors

\begin{tabular}{|c|c|c|c|c|c|c|}
\hline & & \multirow[t]{2}{*}{$\mathbf{n}$} & \multicolumn{2}{|c|}{ The Expression of GSDMD } & \multirow[t]{2}{*}{$\chi^{2}$} & \multirow[t]{2}{*}{$\mathbf{P}$} \\
\hline & & & Negative & Positive & & \\
\hline Gender & $\begin{array}{l}\text { Male } \\
\text { Female }\end{array}$ & $\begin{array}{l}146 \\
98\end{array}$ & $\begin{array}{l}96(39.34 \%) \\
66(27.05 \%)\end{array}$ & $\begin{array}{l}50(20.49 \%) \\
32(13.11 \%)\end{array}$ & 0.066 & 0.7962 \\
\hline Age (years) & $\begin{array}{l}\leq 60 \\
>60\end{array}$ & $\begin{array}{l}113 \\
131\end{array}$ & $\begin{array}{l}81(33.20 \%) \\
81(33.20 \%)\end{array}$ & $\begin{array}{l}32(13.11 \%) \\
50(20.49 \%)\end{array}$ & 2.638 & 0.1347 \\
\hline Distant metastasis & $\begin{array}{l}\text { No } \\
\text { Yes }\end{array}$ & $\begin{array}{l}226 \\
18\end{array}$ & $\begin{array}{l}149(61.07 \%) \\
13(5.33 \%)\end{array}$ & $\begin{array}{l}77(31.56 \%) \\
5(2.05 \%)\end{array}$ & 0.2959 & 0.5865 \\
\hline Histological grade & $\begin{array}{l}\text { Well } \\
\text { Moderately } \\
\text { Poorly }\end{array}$ & $\begin{array}{l}12 \\
181 \\
51\end{array}$ & $\begin{array}{l}6(2.46 \%) \\
115(47.13 \%) \\
41(16.8 \%)\end{array}$ & $\begin{array}{l}6(2.46 \%) \\
66(27.05 \%) \\
10(4.10 \%)\end{array}$ & 6.587 & 0.0371 \\
\hline Tumour stage & $\begin{array}{l}\mathrm{T} 1 \\
\mathrm{~T} 2 \\
\mathrm{~T} 3 \\
\mathrm{~T} 4\end{array}$ & $\begin{array}{l}14 \\
42 \\
94 \\
94\end{array}$ & $\begin{array}{l}6(2.46 \%) \\
24(9.84 \%) \\
60(24.59 \%) \\
72(29.51 \%)\end{array}$ & $\begin{array}{l}8(3.28 \%) \\
18(7.38 \%) \\
34(13.93 \%) \\
22(9.02 \%)\end{array}$ & 9.749 & 0.0208 \\
\hline Nodal stage & $\begin{array}{l}\text { No } \\
\text { NI } \\
\text { N2 }\end{array}$ & $\begin{array}{l}124 \\
73 \\
47\end{array}$ & $\begin{array}{l}26(28.89 \%) \\
42(17.21 \%) \\
28(11.48 \%)\end{array}$ & $\begin{array}{l}13(14.44 \%) \\
31(12.70 \%) \\
19(7.79 \%)\end{array}$ & 6.928 & 0.0313 \\
\hline Lymph nodes invasion & $\begin{array}{l}\text { No } \\
\text { Yes }\end{array}$ & $\begin{array}{l}124 \\
120\end{array}$ & $\begin{array}{l}54(22.13 \%) \\
108(44.26 \%)\end{array}$ & $\begin{array}{l}70(28.69 \%) \\
12(4.92 \%)\end{array}$ & 58.97 & $<0.001$ \\
\hline Vascular invasion & $\begin{array}{l}\text { No } \\
\text { Yes }\end{array}$ & $\begin{array}{l}131 \\
113\end{array}$ & $\begin{array}{l}60(24.59 \%) \\
102(41.80 \%)\end{array}$ & $\begin{array}{l}71(29.10 \%) \\
11(4.51 \%)\end{array}$ & 53.76 & $<0.001$ \\
\hline Clinical stage & $\begin{array}{l}\text { I } \\
\text { II } \\
\text { III } \\
\text { IV }\end{array}$ & $\begin{array}{l}7 \\
96 \\
123 \\
18\end{array}$ & $\begin{array}{l}2(0.82 \%) \\
38(15.57 \%) \\
109(44.67 \%) \\
13(5.33 \%)\end{array}$ & $\begin{array}{l}5(2.5 \%) \\
58(23.77 \%) \\
14(5.74 \%) \\
5(2.05 \%)\end{array}$ & 62.92 & $<0.001$ \\
\hline Tumor location & $\begin{array}{l}\text { Left colon } \\
\text { Right colon } \\
\text { Rectum }\end{array}$ & $\begin{array}{l}81 \\
83 \\
80\end{array}$ & $\begin{array}{l}50(20.49 \%) \\
52(21.31 \%) \\
60(24.59 \%)\end{array}$ & $\begin{array}{l}3 I(12.70 \%) \\
3 I(12.70 \%) \\
20(8.20 \%)\end{array}$ & 3.967 & 0.1376 \\
\hline Tumour size & $\begin{array}{l}<5 \mathrm{~cm} \\
\geq 5 \mathrm{~cm}\end{array}$ & $\begin{array}{l}191 \\
53\end{array}$ & $\begin{array}{l}122(50.0 \%) \\
40(16.39 \%)\end{array}$ & $\begin{array}{l}69(28.28 \%) \\
13(5.33 \%)\end{array}$ & 2.501 & 0.1394 \\
\hline
\end{tabular}

Notes: P-values were calculated by $\chi 2$-test or independent t-testing for continuous data. Significant P-values are printed in bold. 
colon patients with high expressions of GSDMD and colon patients with low expressions of GSDMD. Moreover, the comparison of overall survival was also made between rectal patients with high expressions of GSDMD and rectal patients with low expressions of GSDMD.

\section{Statistical Analysis}

GraphPad software, version 5 was used for statistical analysis. Forms of Data Presentation are mean \pm standard deviation (SD). A Student's $t$-test was applied to assess the statistical significance, while a chi-square test was used to assess the differences of relative GSDMD protein expression in human tissues. By using the Cox proportional hazard model to evaluate the relationship between GSDMD and patients' overall survival (OS). P values $<0.05$ were considered significant.

\section{Results}

The GSDMD Expression is Decreased in Human Colorectal Cancer Tissues and Significantly Associated with CRC Patients' Overall Survival

GSDMD expression was measured in colorectal cancer of human and adjacent tissues. Meeting the selection criteria in the TCGA database is 40 eligible CRC patients. First, we studied the expression of GSDMD in these cases. As expected, compared with the paired adjacent normal mucosa, the GSDMD expression levels in cancer tissues were significantly higher $(* * * \mathrm{P}<0.001$, Figure $2 \mathrm{~A}$ and $\mathrm{B})$. Additionally, IHC was used to examine the samples from 244 patients with CRC by Figure 2C. 66.39\% (162/244) showed high GSDMD expression, whereas 33.61\% (82/ 244) showed low GSDMD expression. Down-regulation of GSDMD was significantly related to histological grade $(\mathrm{P}=0.0371)$, tumor stage $(\mathrm{P}=0.0208)$, nodal stage $(\mathrm{P}=0.0313)$, tumor lymph nodes invasion $(* * * * P<0.0001)$, vascular invasion $(* * * * \mathrm{P}<0.0001)$, and clinical stage $(* * * * \mathrm{P}<0.0001)$ (Table 1$)$. The five-year overall survival (OS) rates of the high and low GSDMD groups were $54.92 \%$ and $86.88 \%$, respectively, and the difference was statistically significant $\quad(* * * \mathrm{P}<0.001$, Figure 2D). Table 2 summarized the Univariate Cox proportional hazard analyses of OS. Univariate analysis showed that distant metastasis, tumor stage, nodal stage, lymph nodes invasion, vascular invasion, clinical stage, and GSDMD were significantly related to shorter OS $(* * * \mathrm{P}<0.001) \quad($ Table 2). With a standardized Cox regression model, the whole factors with statistically significant in the univariate were examined via multivariate Cox regression analysis for relating to OS. Multivariate analysis showed that GSDMD lowly expressed levels, poor tumor stage, distant metastasis, and clinical stage were independently related to OS $(* \mathrm{P}<0.05)$ (Table 3 ). To further investigate if GSDMD can be activated in the CRC, the GSDMD and GSDMD-N expression levels in human colorectal cancer tissue culture with LPS were analyzed. The GSDMD and GSDMD-N expression levels were significantly higher than cultures with normal saline was found. (***P<0.001, Figure $2 \mathrm{E}$ and $\mathrm{F}$ ).

\section{Cleavage of GSDMD is Involved in LPS-Induced Pyroptosis in HT29 Cells}

Further analysis explored whether LPS could induce pyroptosis in HT29 cells. GSDMD, GSDMD-N, Casp1, and cleaved Casp-1 were expressed in HT29 cells which were primed with LPS. As anticipated, the procaspase-1 cleavage of GSDMD in HT29 cells was

Table 2 Univariate Regression Analysis for OS

\begin{tabular}{|c|c|c|}
\hline $\begin{array}{l}\text { Clinicopathological } \\
\text { Characteristics }\end{array}$ & $\mathbf{P}$ & HR (95\% Cl) \\
\hline Gender & 0.436 & $0.849(0.56 \mathrm{I}-\mathrm{I} .283)$ \\
\hline Age & 0.302 & $0.812(0.546-\mid .206)$ \\
\hline Distant metastasis & $<0.0001$ & $23.82(12.00-47.29)$ \\
\hline Histological grade & 0.267 & $1.249(0.843-1.850)$ \\
\hline Tumor stage & $<0.0001$ & $1.989(1.511-2.619)$ \\
\hline Nodal stage & $<0.0001$ & $2.682(2.108-3.4 \mid 2)$ \\
\hline Lymph nodes invasion & $<0.0001$ & $7.647(4.555-12.80)$ \\
\hline Vascular invasion & $<0.0001$ & $6.299(3.925-10.11)$ \\
\hline Clinical stage & $<0.0001$ & $10.37(6.504-16.55)$ \\
\hline Tumor location & 0.572 & $1.073(0.84|-| .368)$ \\
\hline Tumour size & 0.160 & $0.687(0.407-1.160)$ \\
\hline GSDMD & $<0.0001$ & $0.208(0.116-0.375)$ \\
\hline
\end{tabular}

Table 3 Multivariate Cox Regression Analysis for OS

\begin{tabular}{|l|l|l|}
\hline $\begin{array}{l}\text { Clinicopathological } \\
\text { Characteristics }\end{array}$ & P & HR (95\% CI) \\
\hline Distant metastasis & $<0.000 \mathrm{I}$ & $34.83(6.544-185.417)$ \\
Tumour stage & 0.003 & $1.562(1.158-2.107)$ \\
Nodal stage & 0.645 & $1.111(0.709-1.74 I)$ \\
Vascular invasion & 0.026 & $2.274(1.103-4.691)$ \\
Lymph nodes invasion & 0.426 & $1.625(0.492-5.37 I)$ \\
Clinical stage & 0.156 & $1.912(0.780-4.686)$ \\
GSDMD & 0.007 & $0.383(0.191-0.770)$ \\
\hline
\end{tabular}

Notes: At the end of the 5-year follow-up, the 5-year survival rate of 244 patients with colorectal cancer was about 59.86 . 
detected by us. (Figure $3 \mathrm{~A}$ and $\mathrm{B}$ ). There was increasing release of IL-18, IL-1 $\beta$, and LDH after LPS stimulation $\left({ }^{*} \mathrm{P}<0.05\right.$, Figure $\left.3 \mathrm{C}-\mathrm{E}\right)$. We reasoned that the different concentrations of LPS could induce pyroptosis in HT29 cells. Specifically, we found that the GSDMD could cleave in HT29 cell which were treated with higher concentrations of LPS $(* \mathrm{P}<0.05$, Figure 3F and $\mathrm{G})$. In fact, after the morphological change of the apoptosis in HT29 cells, we detected PI-positive cells (Figure $3 \mathrm{H}$ ).

\section{LPS Enhances the Chemosensitivity of L-OHP in HT29 Cells via Inducing Expression of GSDMD}

We explored whether LPS enhanced the chemosensitivity of L-OHP in vivo. The influence of L-OHP dose on
A

$10 \mu \mathrm{g} / \mathrm{mlLPS}$

$\mathrm{CON} \quad 3 \mathrm{~h} \quad 6 \mathrm{~h} \quad 12 \mathrm{~h} \quad 24 \mathrm{~h}$

GSDMD

GSDMD-N

Casp-1

Casp-1

cleaved

GAPDH

C

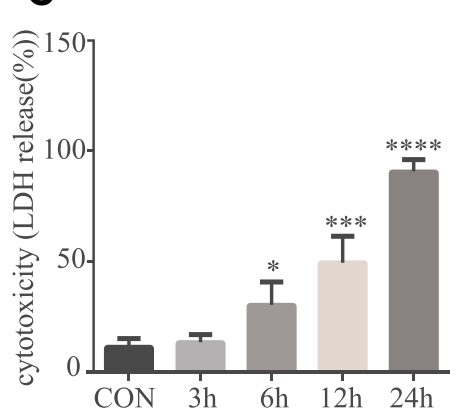

$\mathbf{F}$
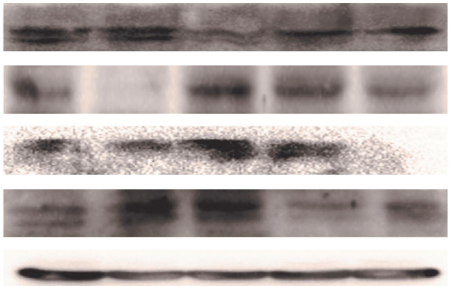

D

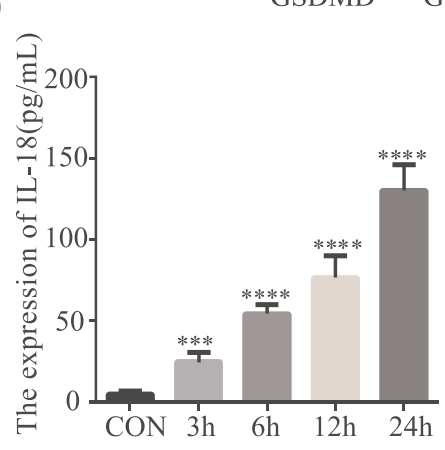

B

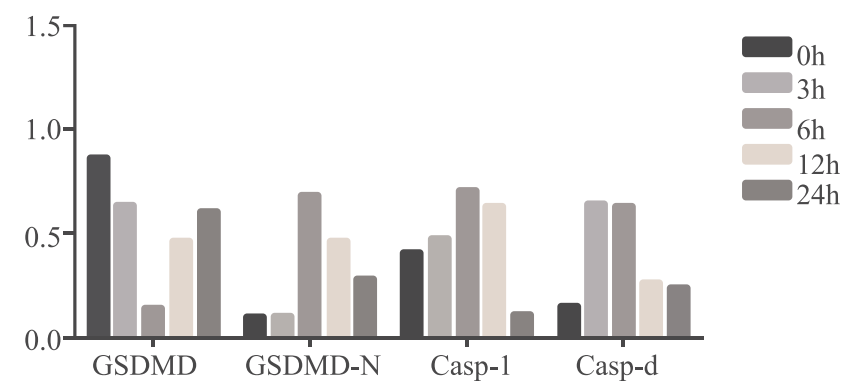

E
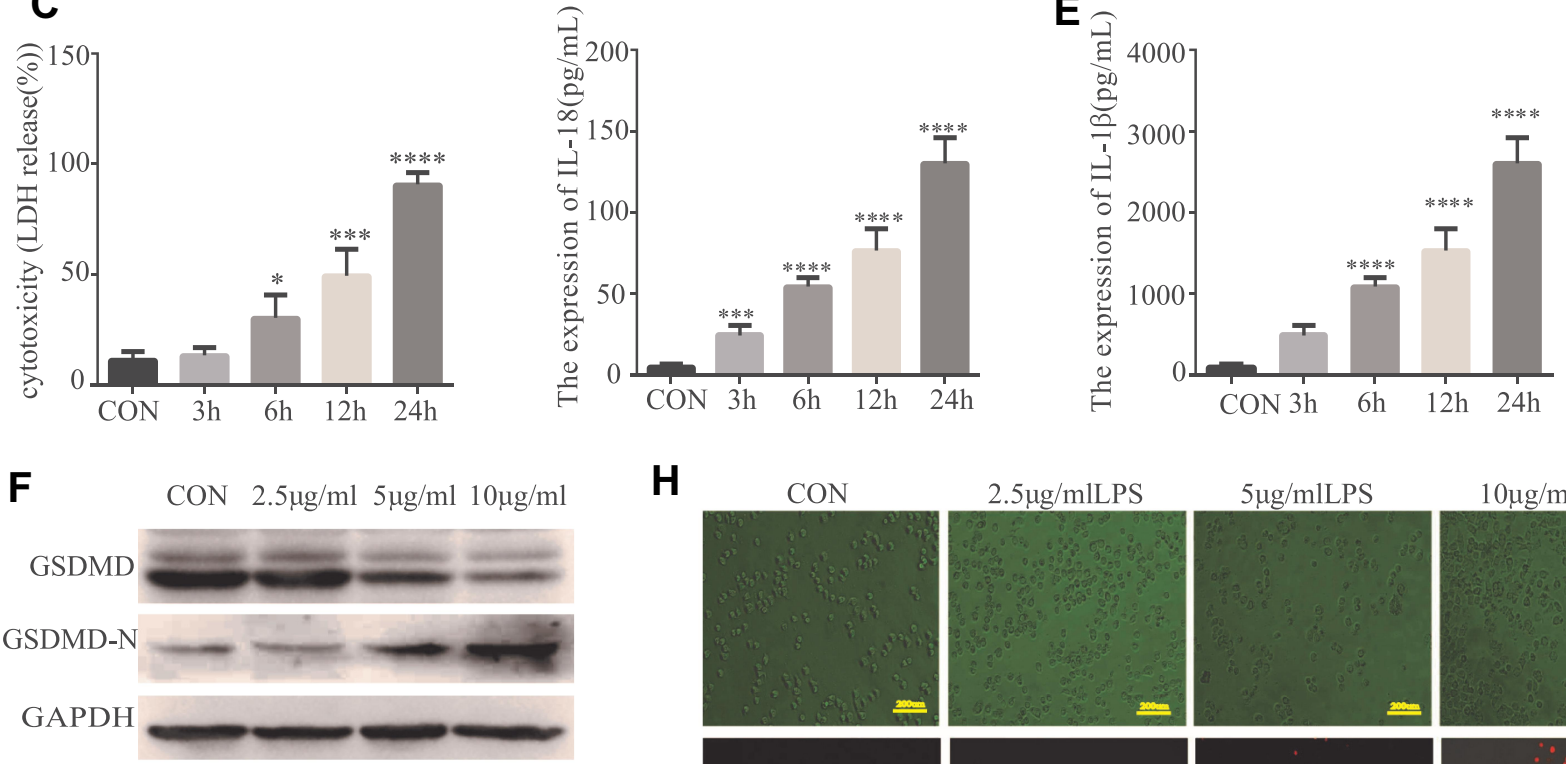

G

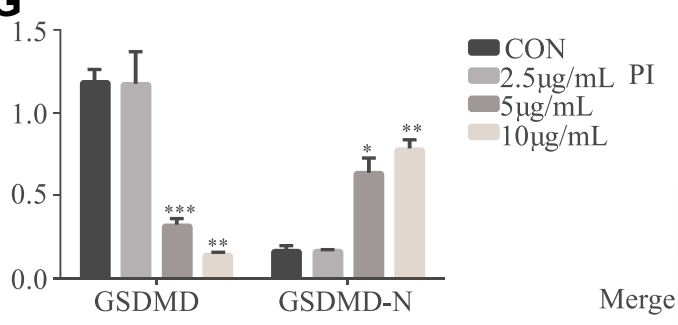

H
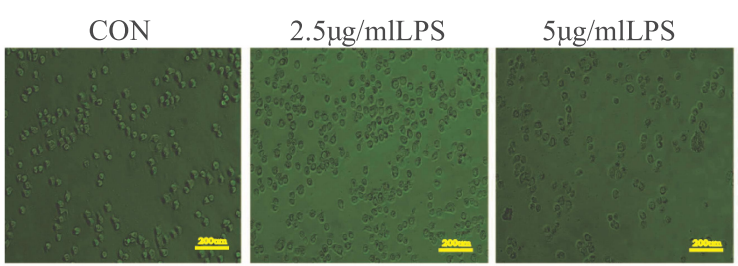

$10 \mu \mathrm{g} / \mathrm{mlLPS}$
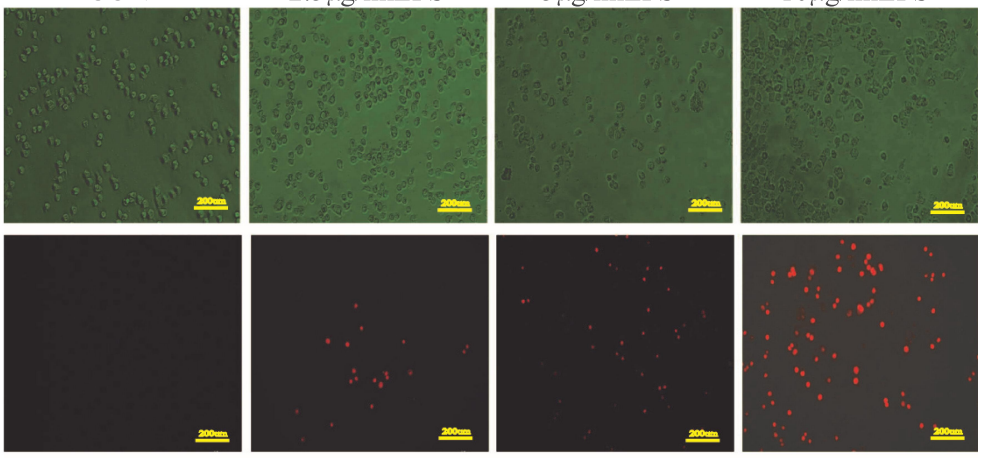

Merge
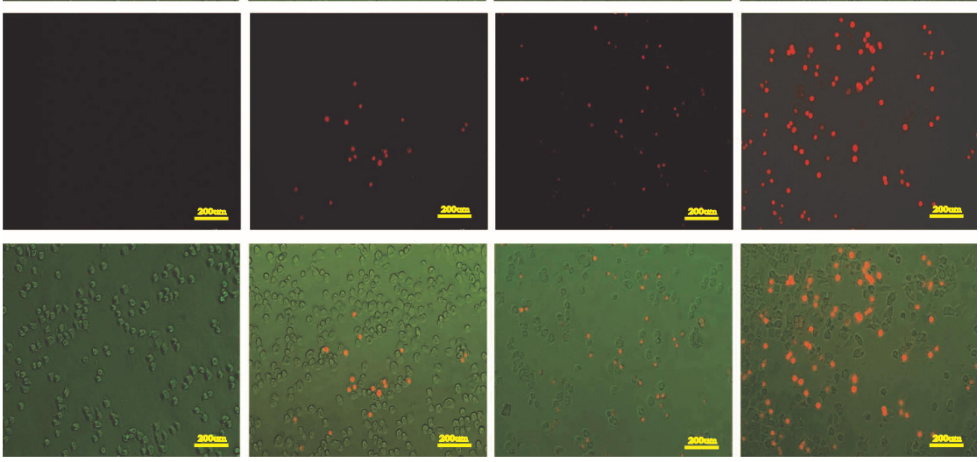

Figure 3 Cleavage of GSDMD is involved in LPS-induced pyroptosis in HT29 cells. (A and B) Western blot analyses were performed to examine the GSDMD expression and pyroptosis-related protein in HT29 cell lines which were treated with LPS $(10 \mu \mathrm{g} / \mathrm{mL})$ at different points in time $(3,6,12$, and $24 \mathrm{~h})(\mathrm{n}=3)$. (C-E) IL-I8, IL-I $\beta$, and LDH secretion were measured by ELISA in HT29 cell lines treated with LPS $(10 \mu \mathrm{g} / \mathrm{mL})$ at different points in time $(3,6,12$, and $24 \mathrm{~h})(\mathrm{n}=6)$. (F and $\mathbf{G}) \mathrm{LPS}(2.5,5,10 \mu \mathrm{g} / \mathrm{mL})$ treat the HT29 cell lines for $6 \mathrm{~h}$, then the GSDMD and GSDMD-N expression in HT29 cell lines was detected by Western blot analysis ( $\mathrm{n=3}$ ). (H) Staining the HT29 cells with PI and analyzing the HT29 cells under a microscope. Results are shown as the mean \pm SD. $* \mathrm{P}<0.05$, **P $<0.0 \mathrm{I}$, ***P $<0.00 \mathrm{I}$, $* * * * \mathrm{P}<0.000 \mathrm{I}$ compared with control group. 
A

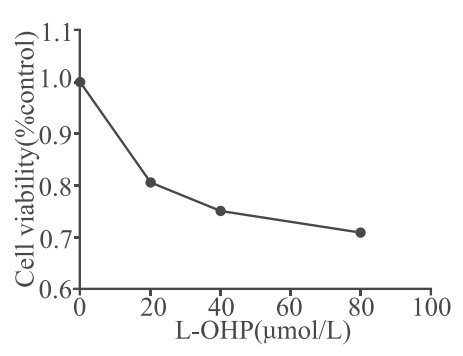

B

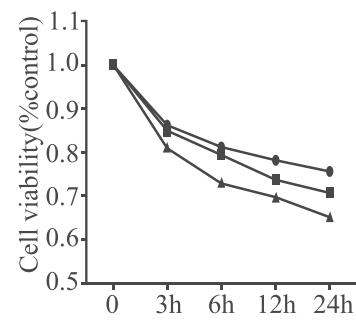

E

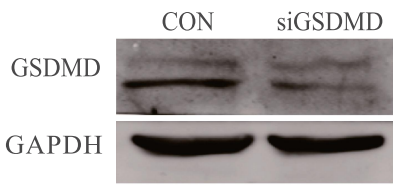

F

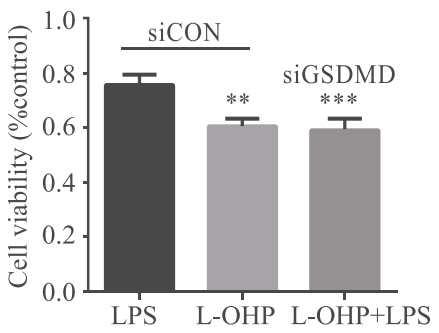

C
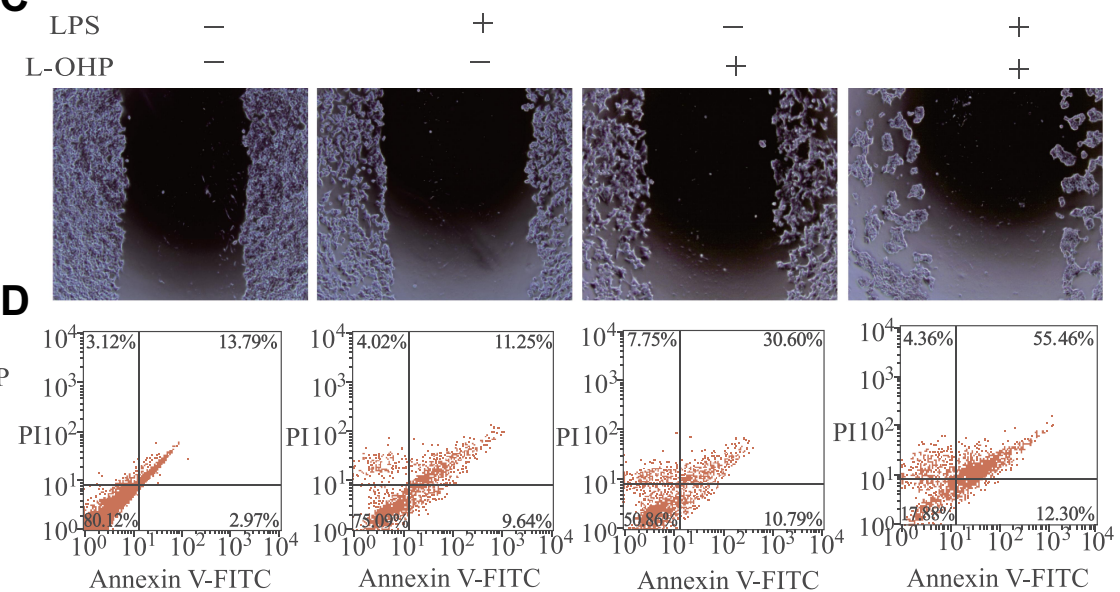

Annexin V-FITC

Annexin V-FITC
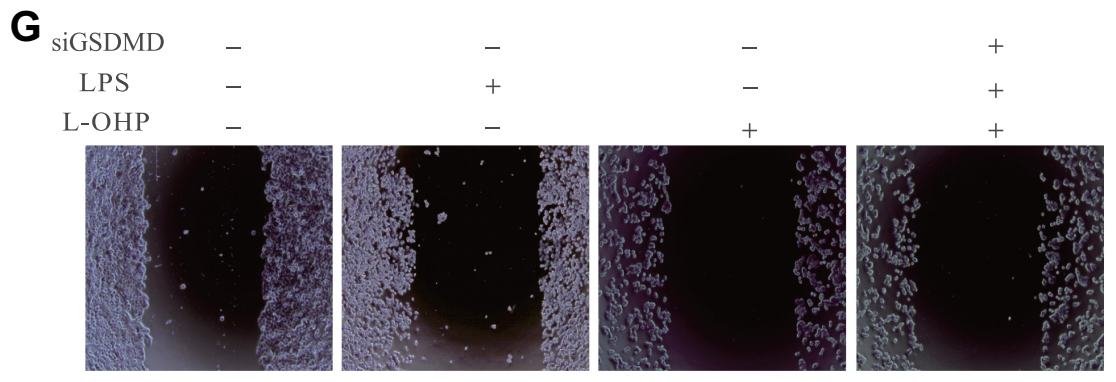

H
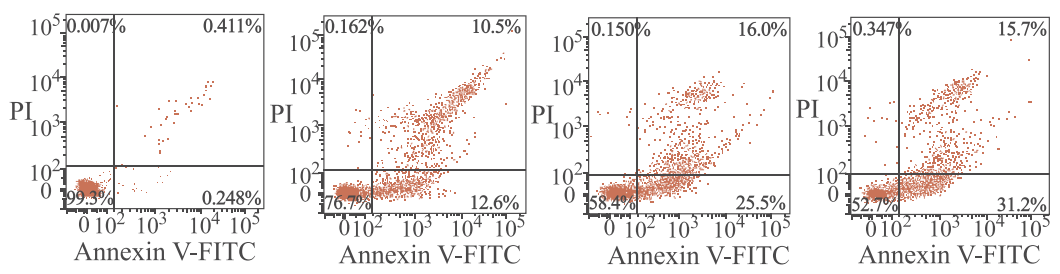

Figure 4 LPS increases Oxaliplatin chemosensitivity in HT29 cells via inducing the expression of GSDMD. (A) The L-OHP concentrations were 20, 40,60 , and $80 \mu$ mol/L for HT29 cells viability based on an MTT assay. The final concentrations of L-OHP (20 $\mathrm{mol} / \mathrm{L})$ were used here and in subsequent experiments unless otherwise stated. (BD) MTT, flow cytometry, and a wound healing assay showed that LPS could enhance the chemosensitivity of L-OHP in HT29 cells. (E) The expression of GSDMD in HT29 cells after transfection with NC (negative control); GSDMD siRNA was examined with Western blot analysis. (F-H) MTT, flow cytometry, and a wound healing assay showed that siRNA-induced silencing of GSDMD could prevent the LPS-induced chemosensitivity of oxaliplatin in HT29 cells. Results shown are mean \pm SD. **p < 0.01 , *** $\mathrm{p}<0.00$ I compared with control group. $\mathrm{n}=3$ in each group.

HT29 cells viability is shown in Figure 4A. Treated the HT29 cells with $10 \mu \mathrm{g} / \mathrm{mL}$ of LPS or $20 \mu \mathrm{mol} / \mathrm{L}$ of L-OHP for $24 \mathrm{~h}$. Then, using MTT, wound healing, and a flow cytometry assay to analyze. As expected, the percentage of cell death increased after LPS or L-OHP treatments compared to the control group (Figure 4BD). Conversely, siRNAs were used to silence the GSDMD expression in HT29 cell lines. siRNAs were used to silence the expression of GSDMD in HT29 cell lines, and Western blotting confirmed that siRNA knocked down the expression of GSDMD (Figure $4 \mathrm{E})$. Interestingly, these results of MTT, wound healing, and flow cytometry assay analysis demonstrate that
LPS did not enhance the chemosensitivity of L-OHP (Figure $4 \mathrm{~F}-\mathrm{H}$ ).

\section{LPS Induces GSDMD-N Activation and Membrane Translocation in HT29 Cells}

Western blots were performed using membrane proteins and total proteins isolated from the cultured HT29 cells treated by LPS. Not surprisingly, LPSinduced GSDMD-N activation, and the membrane translocation was most obvious at $6 \mathrm{~h}$ in the HT29 cells $(* \mathrm{P}<0.05$, Figure $5 \mathrm{~A})$. Figure $5 \mathrm{~B}$ shows PIpositive cells after the apoptotic morphological change of HT29 cells. 
A

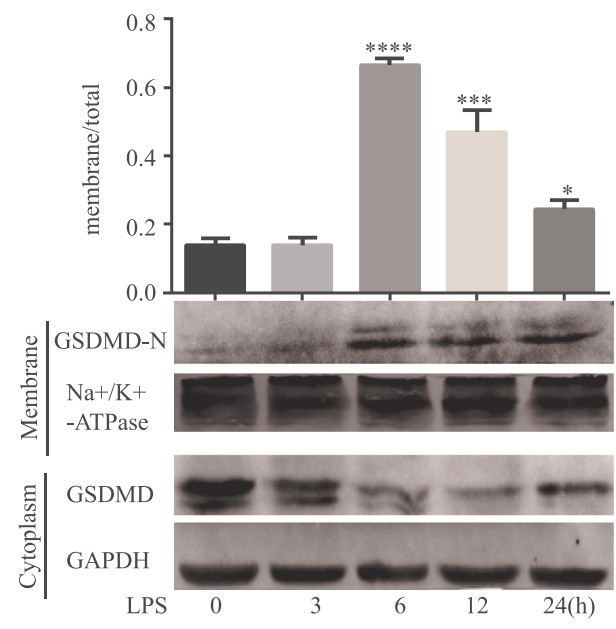

B

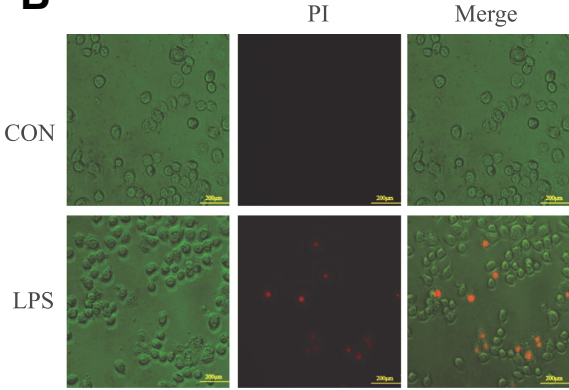

Figure 5 LPS induces GSDMD-N activation and membrane translocation in HT29 cells. (A). Representative immunoblots of total human GSDMD expression and GSDMD$\mathrm{N}$ expression at the surface. Using GAPDH and alpha $\mathrm{Na}+/ \mathrm{K}+\mathrm{ATPase}$ to respectively standardize the expression of the total and surface. As the relative intensity about GSDMD and GSDMD-N, quantification of the expression of total and surface is shown in each fraction. Results shown are mean \pm SD. $n=3$ in each group; *P < 0.05 ; *** $<$ 0.001 ; ****P $<0.000$ I compared with control group. (B). Pyroptosis can be induced by LPS. Staining The HT29 cells with PI and analyzing the HT29 cells under a microscope.

\section{The Role of Pyroptosis in the Formation of Colon Cancer}

The induction procedures of different models by AOM/ DSS are shown in Figure 1A. Figure 1B shows that treated the mice with DSS or AOM combined with DSS in the experiment was significant weight loss than the control mice. At the end of the experiment on day 70, the AOM/DSS treated mice was shown by microscopic examination of colons (Figure 1C). IHC and Western blot showed that the GSDMD/GSDMD-N level was accelerated with inflammation, which displayed a higher expression level in acute/chronic colitis mice and a lower expression in colitis-associated colon carcinogenesis mice, while in normal control mice, it remained very low $\left({ }^{*} \mathrm{P}<0.05\right.$, Figure $\left.1 \mathrm{D}-\mathrm{F}\right)$. The GSDMD expression had no significant relationship with the tumor size $\left({ }^{*} \mathrm{P}<0.05\right.$, Figure $\left.1 \mathrm{G}\right)$.

\section{TNF- $\alpha$ Does Not Induce Pyroptosis}

We found that the expression of TNF- $\alpha$ was higher in the acute/chronic colitis and colitis-related colon cancer mouse models and lower in the normal control mice $\left({ }^{*} P<0.05\right.$, Figure $6 \mathrm{~A}$ and $\left.\mathrm{B}\right)$. This clarifies whether TNF- $\alpha$ could induce pyroptosis. GSDMD and GSDMD-N were expressed in HT29 cells, which were primed with different concentrations of TNF- $\alpha$. The release of IL-18, IL-1 $\beta$, and LDH could result from the cells $(* P<0.05$, Figure $6 \mathrm{C}-\mathrm{E})$. But we were surprised to find that the expression of GSDMD, GSDMD-N, Casp-1, and cleaved Casp-1 in the HT29 cell line treated with TNF- $\alpha$ showed no statistically significant difference (Figure $6 \mathrm{~F}$ and $\mathrm{G}$ ). Ultimately, we did not find PI-positive cells after being primed with different concentrations TNF- $\alpha$ (Figure $6 \mathrm{H}$ and I).

\section{Successful Verification of the Expression of GSDMD}

Through the GEPIA, the results manifest that the GSDMD is expressed lowly in patients with CRC compared with the normal samples $\left({ }^{*} \mathrm{P}<0.05\right.$, Figure 7$)$.

\section{Overall Survival Analysis}

According to the analysis of the Kaplan-Meier Plotter, the overall survival for colon cancer patients with GSDMD expressed highly is better than for colon cancer patients with GSDMD expressed lowly $\left({ }^{*} \mathrm{P}<0.05\right.$, Figure 8A). Likewise, the overall survival for rectal cancer patients expressing GSDMD highly is better than in rectal cancer patients expressing GSDMD lowly $(* \mathrm{P}<0.05$, Figure $8 \mathrm{~B})$. The colon arises from the midgut and the hindgut and the rectum from the cloaca. Studies have shown that the colon and rectum have different blood supply patterns. Therefore, it is necessary to distinguish between colon and rectal cancers. And in the "Kaplan-Meier Plotter", the other researchers also evaluated separately colon and rectal cancer. 
A

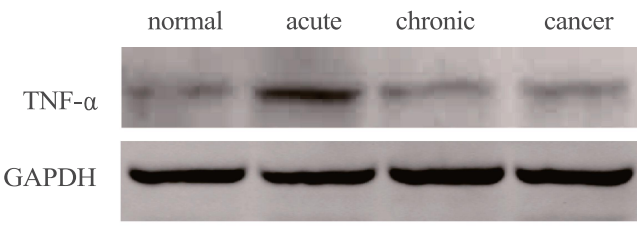

C

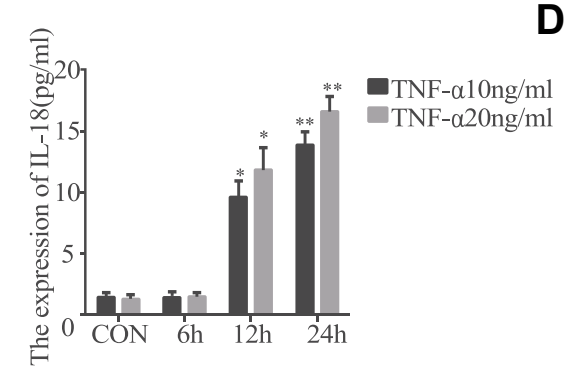

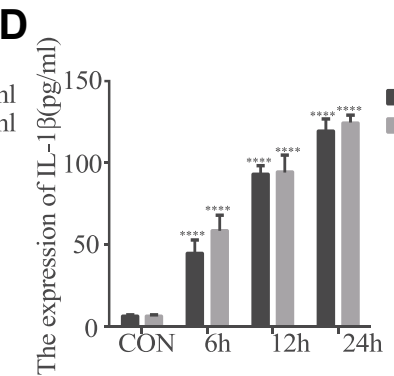

B

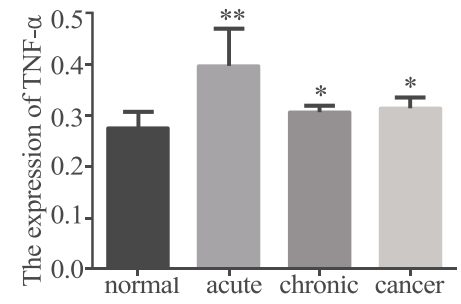

F

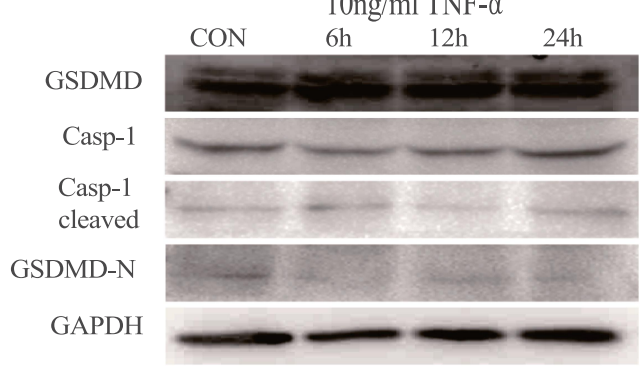

G
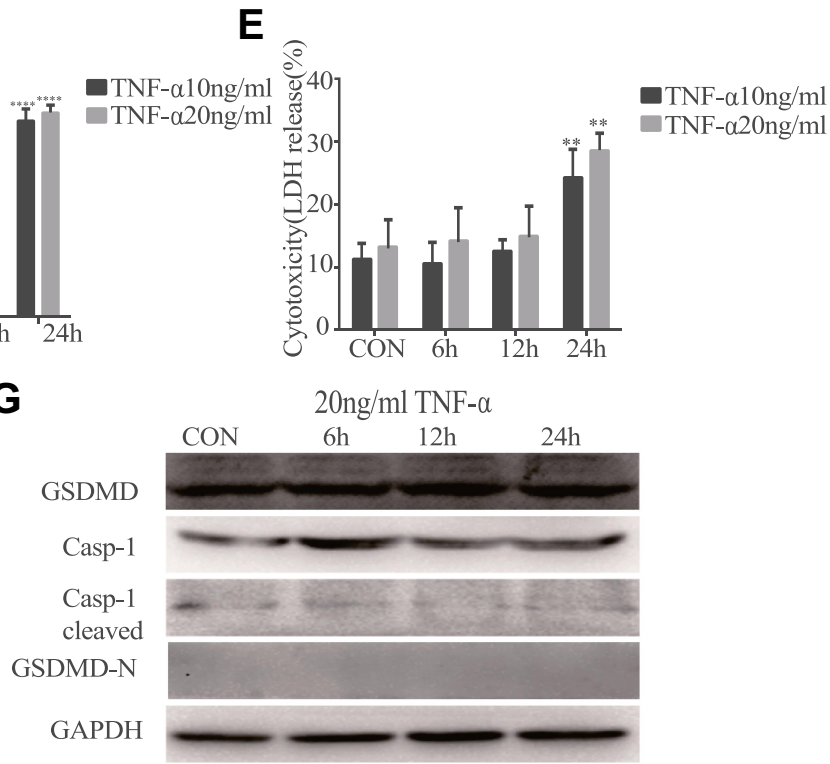

H 10ng/ml TNF- $\alpha$

CON

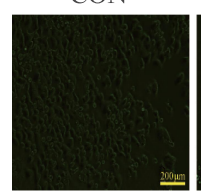

$6 \mathrm{~h}$
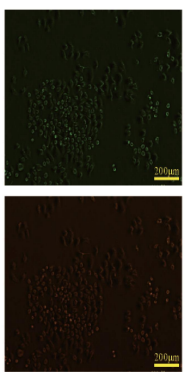

$12 \mathrm{~h}$
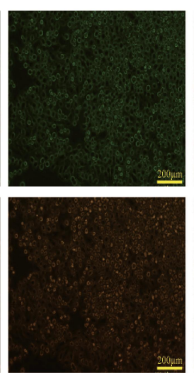

$24 \mathrm{~h}$

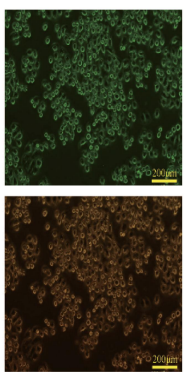

I

CON

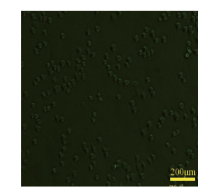

$6 \mathrm{~h}$

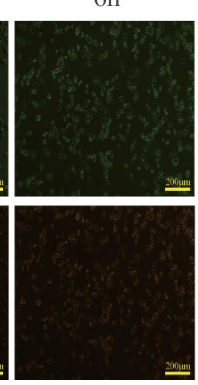

$12 \mathrm{~h}$

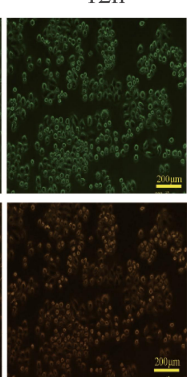

$24 \mathrm{~h}$

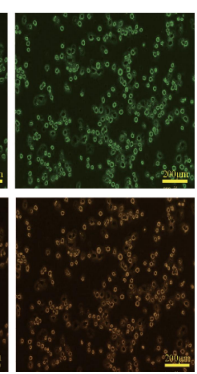

Figure 6 TNF- $\alpha$ cannot induce pyroptosis. (A and B) The expression of TNF- $\alpha$ in acute colitis, chronic colitis, and colitis-associated colon carcinogenesis model tissues were measured by Western blot analysis $(n=3)$. (C-E) IL- I8, IL-I $\beta$, and LDH secretions were measured by ELISA in HT29 cell lines treated with TNF- $\alpha$ (IOng/mL and $20 \mathrm{ng} /$ $\mathrm{mL})$ at different points in time $(6,12$, and $24 \mathrm{~h})(\mathrm{n}=6)$. (F and $\mathbf{G})$ The expression of GSDMD and pyroptosis-related protein in HT29 cell lines treated with TNF- $\alpha(10 \mathrm{ng} / \mathrm{mL}$ and $20 \mathrm{ng} / \mathrm{mL})$ at different points in time $(3,6,12$, and $24 \mathrm{~h})$ were performed by Western blot analysis. (H and I) Staining the HT29 cell lines treated with TNF- $\alpha(10 \mathrm{ng} / \mathrm{mL}$ and $20 \mathrm{ng} / \mathrm{mL}$ ) with $\mathrm{PI}$ and analyzing under a microscope. Data shown are mean $\pm \mathrm{SD}$. $* \mathrm{P}<0.05$; **P $<0.0 \mathrm{I}$; ****P $<0.000 \mathrm{I}$ compared with control group.

\section{Discussion}

We collected CRC tumors and described a new role of LPS in the therapy of CRC, as well as the relationship between the expression of GSDMD and survival in patients with CRC. Specifically, we found that LPSinduced GSDMD expression, while GSDMD sensitized HT29 cells to L-OHP by pyroptosis induction both in vitro and in vivo. These results demonstrate that LPS enhances the chemosensitivity of oxaliplatin in HT29 cells via GSDMD-mediated pyroptosis.

Previous studies from other researchers had implicated GSDMD as a potential gastric cancer suppressor gene. ${ }^{20}$ However, the potential role of LPS in CRC was not yet clear. Our results highlight GSDMD as a characteristic molecule related to the prognosis in 


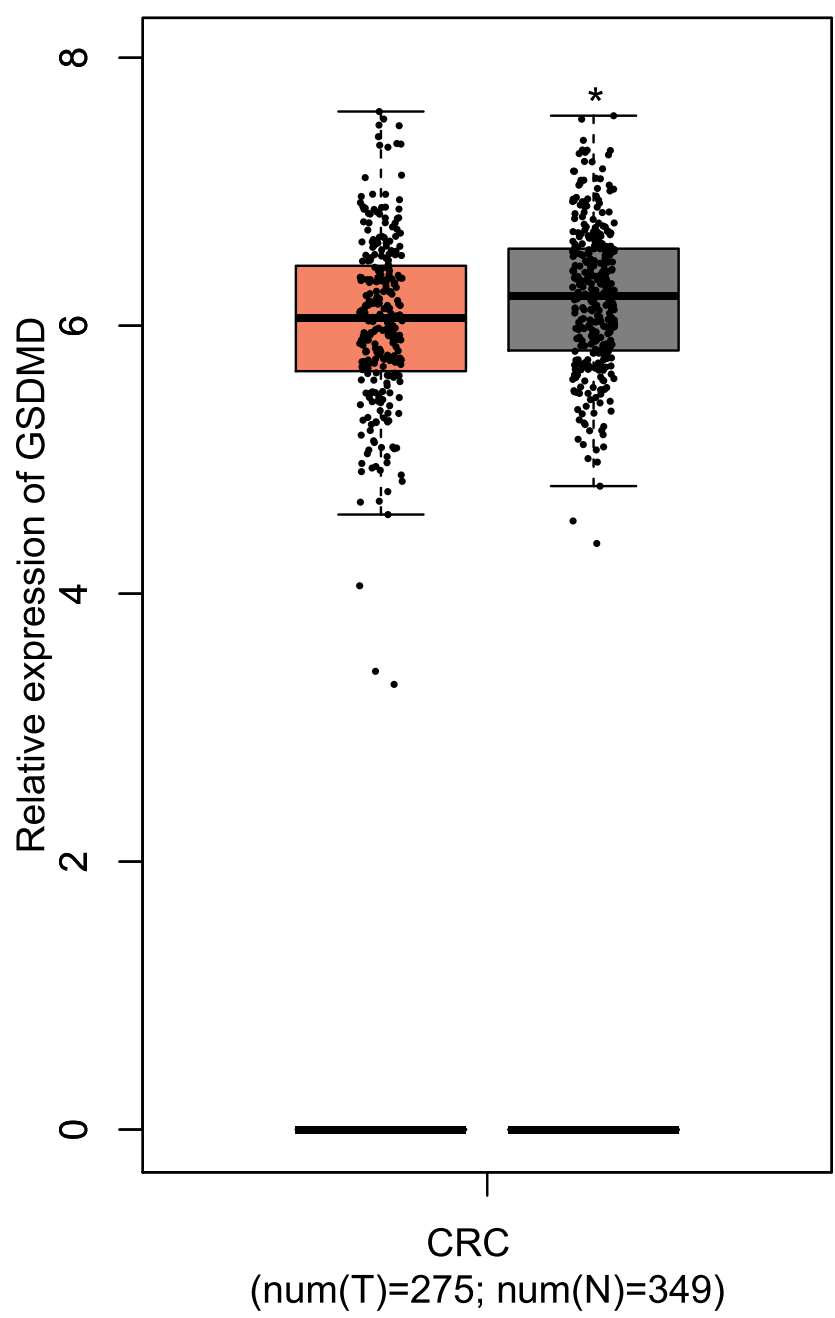

Figure 7 The comparison of expression of GSDMD between the CRC patients and normal samples. $\mathrm{T}=$ tumor, $\mathrm{N}=$ normal. $* \mathrm{P}<0.05$.

patients with CRC. We found that CRC patients with low GSDMD levels had significantly higher survival rates and GSDMD was an independent prognostic factor. An in vitro assay suggested that LPS can enhance the chemosensitivity of L-OHP in HT29 cells and reverse the proliferation of CRC. Using siRNA to knock down the GSDMD expression in HT29. The study results show that silent GSDMD could inhibit the role of LPS in promoting the chemical sensitivity of L-OHP. However, the probable function and mechanism of GSDMD in CRC are still unclear.

Our data reveal that the L-OHP anti-tumor activity is increased by LPS. It may play a synergistic role in the inhibition of growth and promotion of the pyroptosis in
HT29 cells. GSDMD can be cleaved to release an N-terminal fragment by the activation of inflammatory caspase-1 may be one probable mechanism of pyroptosis action. ${ }^{25}$ GSDMD-N binds to the cell membrane to form a pore-like structure. ${ }^{18,26,27}$ It is important for the development of drug chemosensitivity to change the diffusion properties of membranes by these alterations. Cytotoxic compounds, L-OHP included, must travel through their membrane to reach their targets within cancer cells. Therefore, GSDMD can increase the accumulation of L-OHP which may make the inhibition of the growth and promotion of the death in HT29 cells.

The azoxymethane (AOM)/dextran sulfate sodium (DSS) carcinogenic model has been widely used in colorectal cancer research. ${ }^{28-30}$ In follow-up studies, we plan to use this model to investigate the function of pyroptosis in the formation of colon cancer. A protective role of GSDMD in AOM/DSS model for carcinogenesis was suggested by these data. TNF-a was highly expressed in the AOM/DSS model. Pyroptosis is the maturity and excretion of proinflammatory cytokines IL-1 $\beta / 18$ controlled by Inflammasomes and an inflammatory cell death mode induced by Inflammasomes. ${ }^{31}$ Inflammasomes also act as an activation platform for procaspase- $1 .{ }^{32}$ Unlike LPS, TNF- $\alpha$ did not induce pyroptosis. Although TNF- $\alpha$ stimulated the release of increased IL-18, IL-1 $\beta$, and LDH in HT29 cells, the expression of GSDMD, GSDMD-N, Casp-1, and cleaved Casp-1 in the HT29 cell line treated with TNF- $\alpha$ showed no statistically significant difference. We also found after morphological change of the apoptosis in HT29 cells, there are no PI-positive cells. Our findings showed that GSDMD could be activated by LPS but not TNF- $\alpha$.

Pyroptosis induced by LPS may be useful in combination with conventional chemotherapeutic. In addition, we also found that LPS enhances the chemosensitivity of oxaliplatin in HT29 cells via GSDMD-mediated pyroptosis. Nevertheless, the mechanisms of GSDMD-mediated chemosensitization remain unclear. The molecular mechanisms about inhibiting cancer progression and increasing chemosensitization caused by pyroptosis need future studies to explore. 

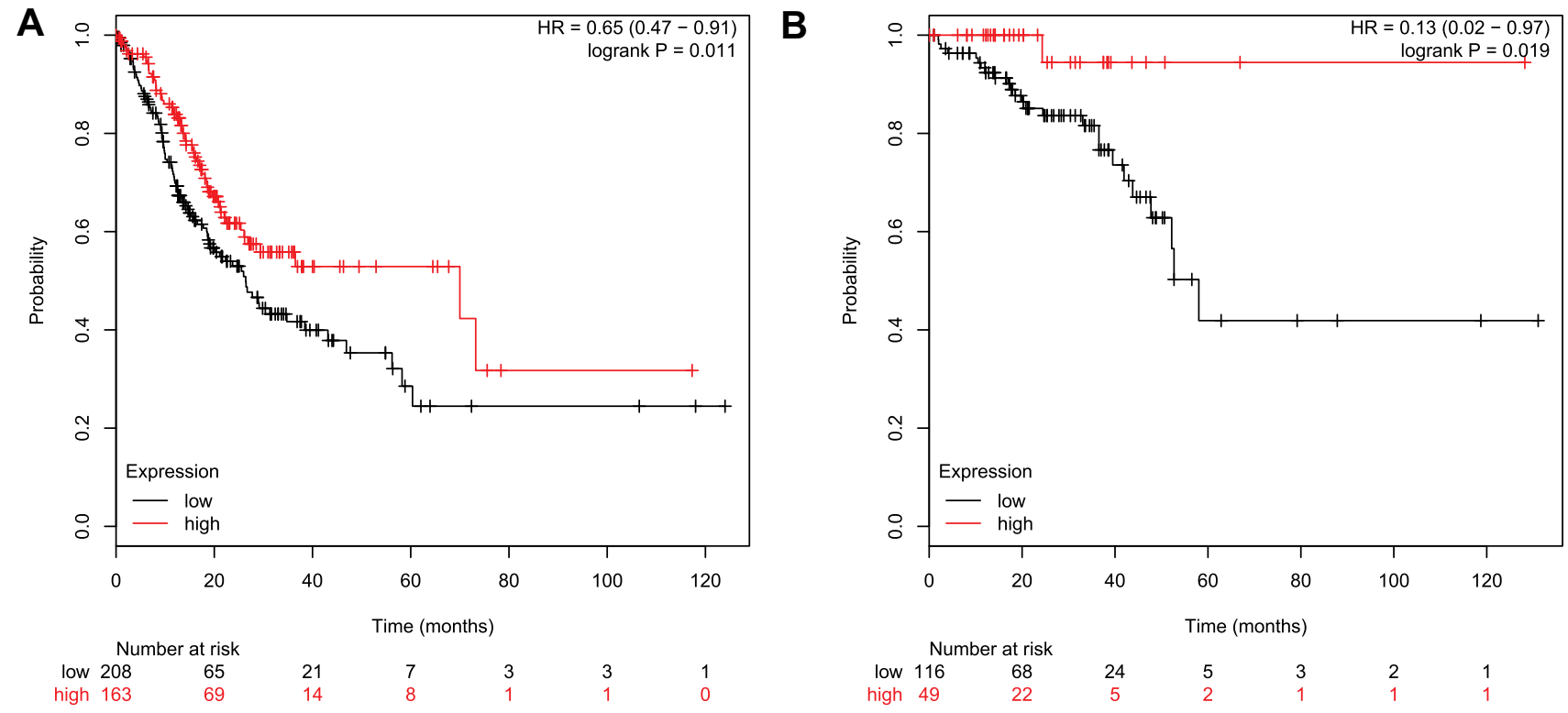

Figure 8 Overall survival analysis in patients with CRC who express GSDMD highly/lowly. (A) The overall survival of expressing highly GSDMD colon cancer patients is better than on expressing lowly GSDMD colon cancer patients. (B) The overall survival for rectal cancer patients expressing GSDMD highly is better than for the rectal cancer patients expressing GSDMD lowly.

\section{Data Sharing Statement}

The datasets used and/or analyzed during the current study are available from the corresponding author on reasonable request.

\section{Ethics Approval and Informed Consent}

The study was approved by the Ethics and the Academic Committees of Hebei Medical University (Shijiazhuang, China). All protocols were approved by the Institutional Animal Care and Use Committee of Hebei Medical University.

\section{Consent for Publication}

The written informed consent was obtained from all patients.

\section{Author Contributions}

All authors made substantial contributions to conception and design, acquisition of data, or analysis and interpretation of data; took part in drafting the article or revising it critically for important intellectual content; gave final approval of the version to be published; and agree to be accountable for all aspects of the work.

\section{Funding}

This work was supported by the National Natural Science Foundation of China (NSFC) grants No. 81372150 (to B. H. L), 91739301 (to M.H.), and 91849102 (to M.H.).

\section{Disclosure}

The authors declare that they have no competing interests.

\section{References}

1. Evelien D, Douglas K. Rex. Advances in CRC prevention: screening and surveillance. Gastroenterology. 2018;154:1970-1984. doi:10.10 53/j.gastro.2018.01.069

2. Keum N, Giovannucci E. Global burden of colorectal cancer: emerging trends, risk factors and prevention strategies. Nat Rev Gastroenterol Hepatol. 2019;16(12):713-732.

3. Aleksakhina SN, Kashyap A, Imyanitov EN. Mechanisms of acquired tumor drug resistance. Biochim Biophys Acta Rev Cancer. 2019;1872 (2):188310. doi:10.1016/j.bbcan.2019.188310

4. Fanale D, Castiglia M, Bazan V, Russo A. Involvement of non-coding RNAs in chemo- and radioresistance of colorectal cancer. $A d v$ Exp Med Biol. 2016;937:207-228.

5. Zhang Y, Huang L, Shi H, et al. Ursolic acid enhances the therapeutic effects of oxaliplatin in colorectal cancer by inhibition of drug resistance. Cancer Sci. 2018;109(1):94-102. doi:10.1111/cas. 13425

6. Tao Y, Shan L, Xu X, et al. Huaier augmented the chemotherapeutic sensitivity of oxaliplatin via downregulation of YAP in hepatocellular carcinoma. J Cancer. 2018;9(21):3962-3970. doi:10.7150/jca.25909

7. Hua Y, Zhu Y, Zhang J, et al. miR-122 targets X-linked inhibitor of apoptosis protein to sensitize oxaliplatin-resistant colorectal cancer cells to oxaliplatin-mediated cytotoxicity. Cell Physiol Biochem. 2018;51(5):2148-2159. doi:10.1159/000495832

8. Sun Y, Ma J, Li D, et al. Interleukin-10 inhibits interleukin-1beta production and inflammasome activation of microglia in epileptic seizures. J Neuroinflammation. 2019;16(1):66. doi:10.1186/s12974019-1452-1

9. Ge Q, Wang S, Zheng Y. Systemic administration of an anti-tumor necrosis factor-alpha monoclonal antibody protects against endotoxin-induced uveitis in rats. Indian J Ophthalmol. 2016;64 (12):873-877. 
10. Yang N, Liang Y, Yang P, Ji F. Propofol suppresses LPS-induced nuclear accumulation of HIF-1alpha and tumor aggressiveness in non-small cell lung cancer. Oncol Rep. 2017;37(5):2611-2619. doi: 10.3892 /or.2017.5514

11. Vlachostergios PJ, Gioulbasanis I, Ghosh S, et al. Predictive and prognostic value of LPS-stimulated cytokine secretion in metastatic non-small cell lung cancer. Clin Transl Oncol. 2013;15(11):903-909. doi:10.1007/s12094-013-1021-5

12. Yokoyama S, Oho AUID, Cai Y, et al. A novel pathway of LPS uptake through syndecan-1 leading to pyroptotic cell death. Elife. 2018;7.

13. Whiteside TL. The tumor microenvironment and its role in promoting tumor growth. Oncogene. 2008;27(45):5904-5912. doi:10.1038/ onc. 2008.271

14. Rathkey JK, Benson BL, Chirieleison SM, et al. Live-cell visualization of gasdermin D-driven pyroptotic cell death. J Biol Chem. 2017;292(35):14649-14658. doi:10.1074/jbc.M117.797217

15. Lee BL, Stowe IB, Gupta A, et al. Caspase-11 auto-proteolysis is crucial for noncanonical inflammasome activation. $J$ Exp Med. 2018;215(9):2279-2288. doi:10.1084/jem.20180589

16. Guo H, Callaway JB, Ting JP. Inflammasomes: mechanism of action, role in disease, and therapeutics. Nat Med. 2015;21(7):677-687.

17. Kayagaki N, Stowe IB, Lee BL, et al. Caspase-11 cleaves gasdermin $\mathrm{D}$ for non-canonical inflammasome signalling. Nature. 2015;526 (7575):666-671. doi:10.1038/nature15541

18. He WT, Wan H, Hu L, et al. Gasdermin D is an executor of pyroptosis and required for interleukin-1beta secretion. Cell Res. 2015;25(12):1285-1298. doi:10.1038/cr.2015.139

19. Kuang S, Zheng J, Yang H, et al. Structure insight of GSDMD reveals the basis of GSDMD autoinhibition in cell pyroptosis. Proc Natl Acad Sci US A. 2017;114(40):10642-10647. doi:10.1073/pnas.1708194114

20. Wang WJ, Chen D, Jiang MZ, et al. Downregulation of gasdermin D promotes gastric cancer proliferation by regulating cell cycle-related proteins. J Dig Dis. 2018;19(2):74-83. doi:10.1111/1751-2980.12576

21. Becker K, Mueller JD, Schulmacher C, et al. Histomorphology and grading of regression in gastric carcinoma treated with neoadjuvant chemotherapy. Cancer. 2003;98(7):1521-1530. doi:10.1002/cncr.11660

22. Tang Z, Li C, Kang B, Gao G, Li C, Zhang Z. GEPIA: a web server for cancer and normal gene expression profiling and interactive analyses. Nucleic Acids Res. 2017;45(W1):W98-W102. doi:10.10 93/nar/gkx247
23. Peng WX, Huang JG, Yang L, Gong AH, Mo YY. Linc-RoR promotes MAPK/ERK signaling and confers estrogen-independent growth of breast cancer. Mol Cancer. 2017;16(1):161. doi:10.1186/ s12943-017-0727-3

24. Hou GX, Liu P, Yang J, Wen S, Franco R. Mining expression and prognosis of topoisomerase isoforms in non-small-cell lung cancer by using Oncomine and Kaplan-Meier plotter. PLoS One. 2017;12(3): e0174515. doi:10.1371/journal.pone.0174515

25. Gaidt MM, Hornung V. Pore formation by GSDMD is the effector mechanism of pyroptosis. EMBO J. 2016;35(20):2167-2169. doi:10. 15252/embj.201695415

26. Wang Y, Gao W, Shi X, et al. Chemotherapy drugs induce pyroptosis through caspase-3 cleavage of a gasdermin. Nature. 2017;547 (7661):99-103. doi:10.1038/nature22393

27. Chen X, He WT, Hu L, et al. Pyroptosis is driven by non-selective gasdermin-D pore and its morphology is different from MLKL channel-mediated necroptosis. Cell Res. 2016;26(9):1007-1020. doi: $10.1038 / \mathrm{cr} .2016 .100$

28. Pan Q, Lou X, Zhang J, et al. Erratum: genomic variants in mouse model induced by azoxymethane and dextran sodium sulfate improperly mimic human colorectal cancer. Sci Rep. 2017;7(1):2784. doi:10.1038/s41598-017-00076-0

29. Ren N, Ji M, Tokar EJ, et al. Haploinsufficiency of SIRT1 enhances glutamine metabolism and promotes cancer development. Curr Biol. 2017;27(4):483-494. doi:10.1016/j.cub.2016.12.047

30. Pathria P, Gotthardt D, Prchal-Murphy M, et al. Myeloid STAT3 promotes formation of colitis-associated colorectal cancer in mice. Oncoimmunology. 2015;4(4):e998529. doi:10.1080/2162402X.2014. 998529

31. Qi X. Formation of membrane pores by gasdermin-N causes pyroptosis. Sci China Life Sci. 2016;59(10):1071-1073. doi:10.10 07/s11427-016-5109-3

32. Martin-Sanchez F, Martinez-Garcia JJ, Munoz-Garcia M, et al. Lytic cell death induced by melittin bypasses pyroptosis but induces NLRP3 inflammasome activation and IL-1beta release. Cell Death Dis. 2017;8(8):e2984. doi:10.1038/cddis.2017.390

\section{Publish your work in this journal}

Cancer Management and Research is an international, peer-reviewed open access journal focusing on cancer research and the optimal use of preventative and integrated treatment interventions to achieve improved outcomes, enhanced survival and quality of life for the cancer patient.
The manuscript management system is completely online and includes a very quick and fair peer-review system, which is all easy to use. Visit http://www.dovepress.com/testimonials.php to read real quotes from published authors. 